\title{
GMR
}

\section{Effect of MSTN propeptide protein on the growth and development of Altay lamb muscle}

\author{
W. Du ${ }^{1}$, Y. Zhang ${ }^{1}$, J.Z. Yang ${ }^{2}$, H.B. Li ${ }^{1}$, J. Xia ${ }^{1}$, N. Li ${ }^{1}$, J.S. Zhang ${ }^{1}$, \\ X.M. Yan ${ }^{1}$ and Z.Y. Zhou ${ }^{1}$ \\ ${ }^{1}$ Xinjiang Academy of Animal Science, Urumqi, China \\ ${ }^{2}$ Agriculture Lab, University of Hawaii at Manoa, Honolulu, HI, USA \\ Corresponding author: Y. Zhang \\ E-mail: zhanyang2015@126.com \\ Genet. Mol. Res. 15 (2): gmr.15027778 \\ Received October 5, 2015 \\ Accepted November 23, 2015 \\ Published June 24, 2016 \\ DOI http://dx.doi.org/10.4238/gmr.15027778
}

\begin{abstract}
Prokaryotic expression technology was used to express maltose-binding protein binding myostatin (MSTN) propeptide fusion protein. Six disease-free Altay lambs were used in this study. The right leg gastrocnemii were injected with MSTN recombinant propeptide protein. The left leg gastrocnemii (the control group) were injected with the same dose of phosphate based saline. The lambs were fed during four months under the same conditions and then slaughtered. Gastrocnemius samples were hematoxylin-eosin stained and the size of the muscle fibers was measured. A real-time polymerase chain reaction (RT-PCR) showed that single gastrocnemius cells in the experimental group had an average area of $1163.01 \mu \mathrm{m}^{2}$, while it was $845.09 \mu \mathrm{m}^{2}$ in the control group $(\mathrm{P}<0.05)$. This indicates that the MSTN propeptide biological agents had an inhibitory effect on MSTN. In order to reveal its mechanism, RT-PCR was conducted to detect the expression of the differentiation-associated genes MyoD, Myf5, Myogenin, p21, and Smad3. The results showed that, in the MSTN propeptide biological agent injected group, expression levels of MSTN, Smad3, and p21 were lower than the control group, while Myf5, MyoD, and Myogenin were higher compared to the control group. This indicates that, when
\end{abstract}


expression of the MSTN gene was inhibited, muscle cell differentiation and growth can be promoted by $\operatorname{Smad} 3$ up-regulated expression of Myf5, MyoD, and Myogenin.

Key words: MSTN; Propeptide; Real-time-PCR

\section{INTRODUCTION}

In 1997, McPherron et al. reported a new transforming growth factor (TGF) beta, which was cloned from mouse skeletal muscle cDNA library. By comparisons of protein homology, it was shown to be a new member of the TGF- $\beta$ superfamily, and was named growth/differentiation factor-8 (GDF-8) (McPherron et al., 1997). The gene mutational Pyrmont and Belgian Blue cattle show a significant double-muscled phenomenon (Kambadur et al., 1997). Myostatin (MSTN) gene silenced mice (Magee and Sayegh, 1997) and zebrafish, which were bred in the laboratory, also showed significant muscle hyperplasia. Skeletal muscle-specific over-expression of MSTN propeptide in transgenic mice resulted in a dramatic increase in skeletal muscle mass (Lee and McPherron, 2001; Yang et al., 2001). In mice, a two-fold increase in muscle growth following injection of the mutated propetide in neonatal stages lasted for about five weeks after injection, primarily as the result of fiber hypertrophy (Yang et al., 2001; Lee and McPherron, 2011). These results suggest that a reduction of myostatin activity by bone morphogenetic protein 1/ Tolloid proteinase-resistant myostatin propeptide can be an effective way to promote muscle growth. Li et al. (2010) compared eukaryotic expression with monoclonal antibody technology. Prokaryotic expression technology has a large expression quality and has the advantages of easy purification, low cost, and an easy industrialized production process. In view of this, prokaryotic expression technology was used in the present study, to express maltose binding protein (MBP) binding MSTN propeptide fusion protein. The protein was injected into Altay lambs with the aim to investigate whether, in the early days of muscle development, over-expression of MSTN propeptide in lamb skeletal muscle can speed up the growth rate of muscle, and thus, provide a scientific basis for increased muscle production.

\section{MATERIAL AND METHODS}

pMal-MProM recombinant bacteria were kept by laboratory. Protein Marker, IPTG, protein purification kit, embedding agent, alcohol, ammonia, hematoxylin dye, eosin dye, OTC viscose, restriction endonuclease XhoI, BamHI, and T4 DNA ligase were purchased from Takara Bio Engineering Co., Ltd. in Dalian. Taq DNA polymerase was purchased from Promage Company.

\section{Protein expression and purification}

Using pMal-MProM recombinant bacteria (kept and maintained at Xinjiang Academy of Animal Science), induced temperature and time that may affect pMal-MProM expression were investigated. At $37^{\circ} \mathrm{C}$, a final concentration of $0.5 \mathrm{mM}$ IPTG (Isopropyl $\beta$ -D-1-Thiogalactopyranoside) was added. The bacteria were cultured for $5 \mathrm{~h}$, at which point the expression was optimal. Following this methodology, Rosetta protein was expressed. Following centrifugation (1300 g), the bacteria, in pellet form, were re-suspended in a cell lysis 
buffer containing protein inhibitors. Following sonication on ice, the supernatant, containing an inducible protein, was retrieved and the protein was purified by affinity chromatography. At this time, $1 \mathrm{~mL}$ maltose resin gel was added to the chromatography column. The column was first washed with distilled water three times, and then washed three times in gel buffer, until the column was equilibrated. The supernatant containing the target protein was then slowly added, so that the protein could adsorb the gel. The gel buffer was used to wash the column approximately 10 times to re-balance, and then $0.5 \mathrm{mM}$ maltose was used to wash the maltose resin gel five additional times to create the hybrid protein. Finally, the targeted protein was eluted by $10 \mathrm{mM}$ maltose.

\section{Injection of MSTN propeptide}

Six healthy and disease-free Altay sheep were selected; ewes had sufficient milk to ensure normal growth and development of the lambs. One week (7-10 days) after birth, the selected lambs were injected with MSTN propeptide protein, MSTN propeptide protein was injected into the lambs. The gastrocnemius of each left leg was used as the control group by injecting $0.5 \mathrm{~mL}$ phosphate based saline (PBS). In contrast, the gastrocnemius of the right leg, the experimental group, was injected with $0.5 \mathrm{~mL}$ MSTN propeptide. During the second week, booster injections were administered in similar places. During the entire experiment, an adequate energy and protein feed supply was ensured for ewes. Likewise, sanitation control, adequate exercise and temperature was ensured. After feeding for four months, all six experimental lambs were slaughtered and measured. Part of the tissue was embedded for hematoxylin-eosin (H\&E) staining to measure muscle fiber size, while the other part was flash frozen in liquid nitrogen and stored in a $-80^{\circ} \mathrm{C}$ freezer until further analysis.

\section{Muscle sectioning, immunofluorescence, and measurement}

Each sample to be used for frozen sectioning was coated with Tissue-Tek OCT and cut at $8-\mu \mathrm{m}$ thickness using a freezing microtome (CM1100, Leica, Berlin, Germany) at $-20^{\circ} \mathrm{C}$. The slices were stained with H\&E. All sections were photographed using a digital microscope (Nikon, Berlin, Germany). The myofiber diameter and the area of cross-section (CSA) were measured using Image-Pro Plus v. 6.0 (Media Cybernetics, Bethesda, MD, USA).

\section{RNA isolation and RT-PCR}

Total RNA of all samples from the six Altay lambs was isolated using the TRIzol (Invitrogen, Chicago, IL, USA) method. Expression levels of MSTN, Myf5, and MyoD were detected after MSTN propeptide treatment, and glyceraldehyde-3-phosphate dehydrogenase (GAPDH) was used as inner control. Reactions of quantitative real-time PCR (qRT-PCR) were performed using an iCycler IQ5 Multicolor detection system (Bio-Rad, Chicago, IL, USA). The qRT-PCR contained $1 \mu \mathrm{L}$ cDNA template, $12.5 \mu \mathrm{L}$ SYBR Premix Ex Taq, 10.5 $\mu \mathrm{L}$ sterile water, and $0.5 \mu \mathrm{L}$ gene specific primers (Table 1 ). The thermal cycling parameters were one cycle at $95^{\circ} \mathrm{C}$ for $30 \mathrm{~s}, 40$ cycles of $95^{\circ} \mathrm{C}$ for $10 \mathrm{~s}$, and $60^{\circ} \mathrm{C}$ for $40 \mathrm{~s}$. The qRT-PCR analysis of each sample was repeated three times. The relative mRNA expression levels of the genes of interest were calculated using the normalized relative quantification method followed by $2^{-\Delta \Delta C t}$ (Livak and Schmittgen, 2001). 


\begin{tabular}{|c|c|c|c|}
\hline Gene & Primer sequence $\left(5^{\prime} \rightarrow 3^{\prime}\right)$ & Product length $(\mathrm{bp})$ & Annealing temperature $\left({ }^{\circ} \mathrm{C}\right)$ \\
\hline \multirow{2}{*}{ GAPDH } & F: CAAGTTCCACGGCACAGTCA & \multirow{2}{*}{248} & \multirow{2}{*}{60} \\
\hline & R: GGTTCACGCCCATCACAAA & & \\
\hline \multirow[t]{2}{*}{ Myogenin } & F: AACCAGGAGGAGCGTGATCT & \multirow[t]{2}{*}{175} & \multirow[t]{2}{*}{58} \\
\hline & R: GATTGTGGGCATCTGTAGGG & & \\
\hline \multirow[t]{2}{*}{$p 21$} & F: GGAACTTCGACTTTGTCACCG & \multirow[t]{2}{*}{321} & \multirow[t]{2}{*}{59} \\
\hline & R: AGATCAGCCTGCGTTTGGA & & \\
\hline \multirow[t]{2}{*}{ MyoD } & F: GCTCCAGAACCGCAGTAAGT & \multirow[t]{2}{*}{194} & \multirow[t]{2}{*}{57} \\
\hline & R: CGAAACACGGGTCATCATAGA & & \\
\hline \multirow[t]{2}{*}{ Smad3 } & F: GCCGACAAAGACAAATAAAAGG & \multirow[t]{2}{*}{97} & \multirow[t]{2}{*}{59} \\
\hline & R: TCAGGGGAAAGATGACAGACC & & \\
\hline \multirow[t]{2}{*}{$M S T N$} & F: GATTTTGGGCTTGATTGTGATG & \multirow[t]{2}{*}{204} & \multirow[t]{2}{*}{60} \\
\hline & R: ACCTTTGGGGTTTGCTTGG & & \\
\hline \multirow[t]{2}{*}{ Myf5 } & F: CAGCAGAAACGCAGTAAAACC & \multirow[t]{2}{*}{120} & \multirow[t]{2}{*}{58} \\
\hline & R: TTAGCATATCCCACCGCAAC & & \\
\hline
\end{tabular}

\section{Design and synthesis of primers}

Referring to the mRNA sequences of sheep GAPDH, the Myogenin, $p 21$, MyoD, Smad3, MSTN, and Myf5 genes published in GenBank were selected. The primer design software PRIMER 5.0 was used to design primers. The primer sequences are shown in Table 1.

\section{Data analysis}

Differences between the groups were evaluated by the two-tailed Student $t$-tests and P $<0.05$ was considered significant. All data are reported as mean $\pm \mathrm{SE}$.

\section{RESULTS}

\section{Analysis of protein expression product}

The recombinant bacterial lysates were subjected to SDS-PAGE electrophoresis. The protein expression analysis showed that the induced bacteria had a thick protein band at 75 $\mathrm{kDa}$, close to the theoretically-speculated relative molecular mass of expression product. The results of this analysis are shown in Figure 1.

\section{Analysis of tissue sections}

There were no significant differences in weight between the right (MSTN-injected) and left (PBS-injected) leg of the lambs. The CSAs of a total of 1000 muscle fibers analyzed in 6 performed by Motic Images Advanced 3.2 image processing software, showed that the average single cell areas of gastrocnemius in the experimental and control groups were 1163.01 and $845.09 \mu \mathrm{m}^{2}$, respectively $(\mathrm{P}<0.05)$ (Figures 2 and 3 ). This indicates that MSTN propeptide played a certain role in muscle production. Likely, the administered dose was not high enough to produce a significant difference in leg weight between the experimental and control groups. 


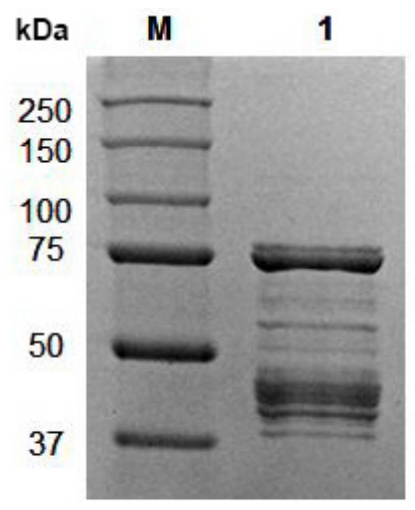

1. MBP-sMSTNProM

2. M: $250 \mathrm{kDa}$ PROTEIN MARKER

Figure 1. Protein expression and purification.

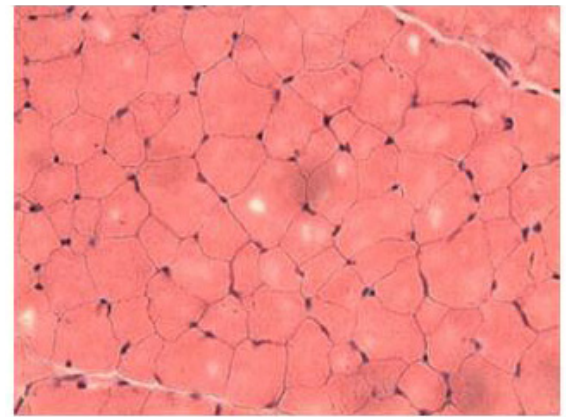

A

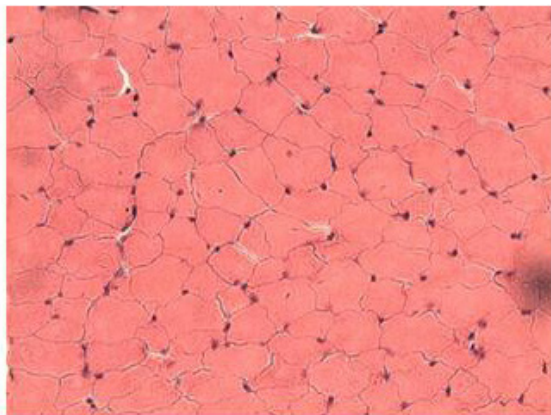

B

Figure 2. Effects of MSTN propeptide on lamb muscle fiber $(\mathrm{N}=10)$. Shown are muscle sections stained by H\&E in the MSTN propeptide treatment group A. and in the control group B. The magnification is 40X in both cases.

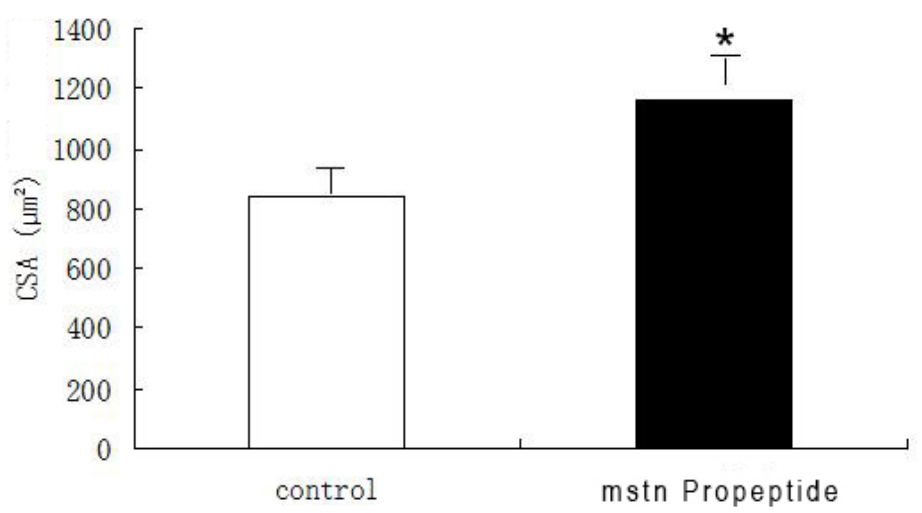

Figure 3. Effects of myostatin propeptide on the muscle fiber cross-sectional area (CSA). An asterisk indicates a significant difference $(\mathrm{P}<0.05)$. 


\section{RT-PCR analysis}

Through the injection of MSTN propeptide biological agent, we were able to inhibit $M S T N$ expression to a certain extent. The expression of the differentiation-associated genes MyoD, Myf5, Myogenin, $p 21$, and Smad3 (Figure 4) showed that the expression levels of MSTN, Smad3, and $p 21$ were lower in the experimental group than in the control group. On the other hand, the expression levels of Myf5, MyoD, and Myogenin were higher in the experimental group than in the control group. This indicates that, when the MSTN gene expression was suppressed, expression levels of Myf5, MyoD, and Myogenin were up-regulated by Smad3, resulting in a promotion of muscle cell differentiation and growth.
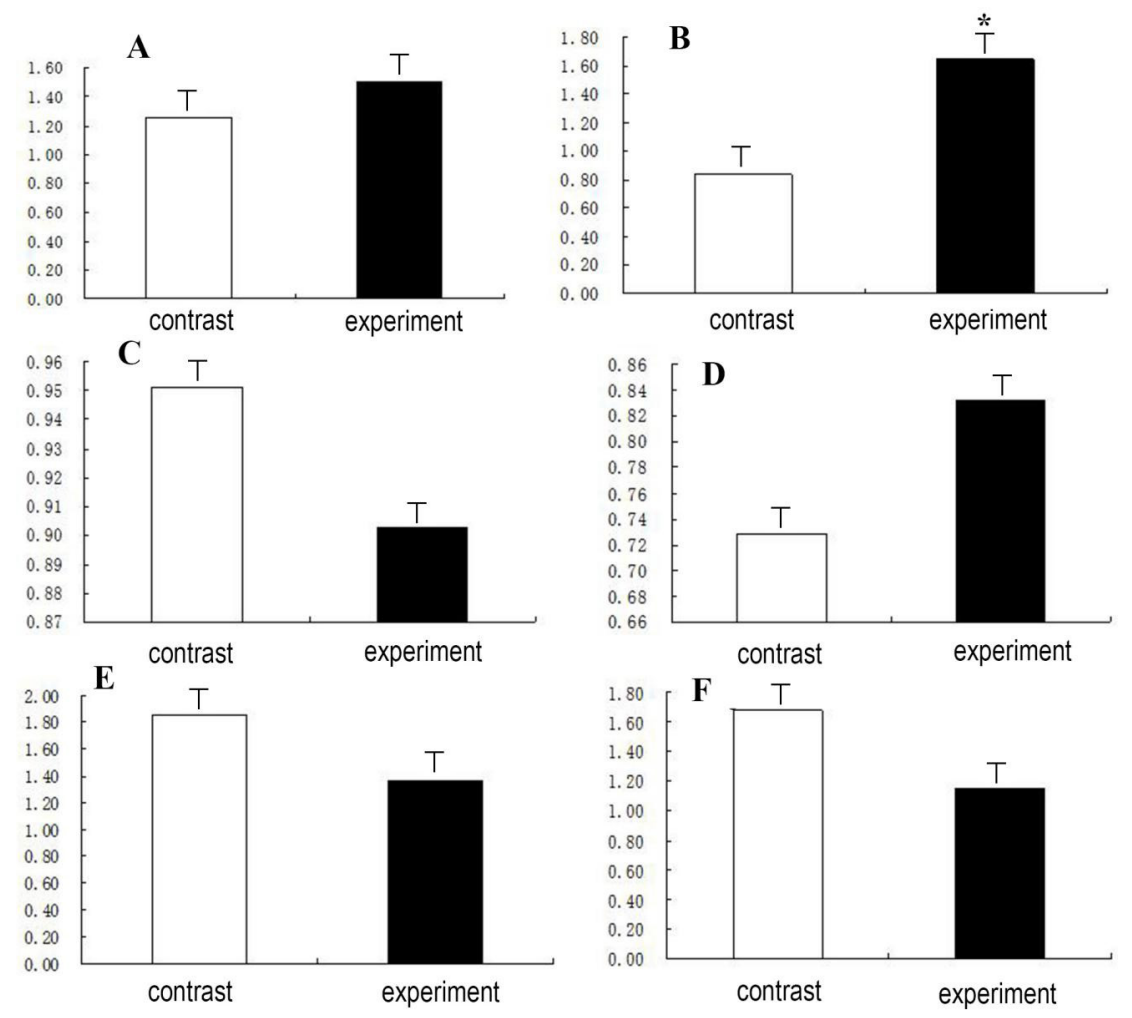

Figure 4. RT-PCR detecting the expression of differentiation-associated genes Myf5 (A), MyoD (B), MSTN (C), Myogenin (D), p21 (E), and Smad3 (F). An asterisk indicates a significant difference $(\mathrm{P}<0.05)$.

\section{DISCUSSION}

Muscle cell differentiation and growth are bidirectionally regulated by a number of positive and negative regulators. The insulin-like growth factor (IGF) axis is considered to play an important positive role in regulating the differentiation and growth of muscle cells. Expression of IGFs increased in the formation of secondary fibers and their role is to stimulate myoblast proliferation and differentiation, and gene family regulation of myogenic determination genes (such as MyoD). MyoD includes four genes; MyoDl (Myf3), Myogenin 
(MyoG), Myf5, and Myf6 (herculinh or MRF4). MyoD and Myf5 share similar roles in the process of myogenesis, while Myogenin and Myf6 control muscle differentiation (Tian et al., 2005).

In this experiment, MSTN propeptide biological agent was injected into lambs. We found that this agent inhibited MSTN to certain extent; the average CSAs of the gastrocnemius were significantly larger in the experimental group $\left(1163.01 \mu \mathrm{m}^{2}\right)$ than in the control group $\left(845.09 \mu \mathrm{m}^{2}\right)$. To further study the active mechanism, we used RT-PCR to detect the expression of genes associated with differentiation; MyoD, Myf5, Myogenin, p21, and Smad3. The results showed that MSTN gene expression was suppressed by Smad3-increased expression of Myf5, $M y o D$, and Myogenin.

These results could be brought about through a number of mechanisms: 1 . The decreased MSTN expression resulted in a general reduction in cell inhibition. 2. MSTN transformed the signal into the nucleus through the mediation of the smad protein to act on the regulatory regions of target genes (Liu et al., 2001; Langley et al., 2002). Smad3 is the downstream target gene of the MSTN receptor complexes, participating in MSTN-mediated regulation of myoblast differentiation (Ge et al., 2011). Therefore, it is possible that decreased MSTN expression levels resulted in a reduction in Smad3 (MSTN has been shown to inhibit the differentiation of skeletal muscle satellite cells by Smad3 down-regulated MyoD expression). Following the reduced expression of $\mathrm{Smad} 3$, cell proliferation was faster than normal in cells (Gulbis et al., 1996). 3. MSTN expression levels decreased and the negative feedback effects on $M y o D$ decreased, resulting in increased expression levels of MyoD, Myf5, and Myogenin. The $M y o D$ concentration during cell proliferation was greater than the normal cell concentration and may be accelerating cell proliferation. After MyoD gene interference, the MSTN gene expression was also reduced and the cell growth rate was the same as the normal growth rate. On the other hand, after MSTN interference, the expression of $M y o D$ increased and skeletal muscle satellite cells grew rapidly, resulting in a growth rate that was higher than the normal cell growth rate. 4. MSTN expression levels decreased, resulting in reduced expression levels of $p 21$. The $p 21$ gene regulates the cell cycle mainly through two aspects: $\mathrm{p} 21$ combines with cyclin, cyclin-dependent kinases (CDK), and proliferating cell nuclear antigen (PCNA) to form a tetramer complex. This complex can effectively inhibit the activity of various cyclinCDK complexes causing the cell cycle to arrest in the G1-phase (Gulbis et al., 1996). In addition, p21 can combine with the PCNA subunit of DNA polymerase at CDK deficiency to block DNA replication. Once the $p 21$ gene fuction was removed, it allowed the cells to proliferate in the presence of negative growth signals. It is known that, as the downstream effector of p53, p21 is primarily related to radiation-induced Gl-phase arrest. It makes the cells exit the cell cycle to coordinate cell cycle progression, therefore, it is considered a cell proliferation-suppressing gene (El-Deiry et al., 1993).

In conclusion, our study confirmed that the MSTN propeptide played a certain role in the differentiation and proliferation of Altay lamb muscle. We detected the expression of differentiation-associated genes MyoD, Myf5, Myogenin, $p 21$ and Smad 3 by RT-PCR, to reveal their mechanism of action. Through this experiment we believe that using MSTN propeptide to inhibit MSTN gene expression might be a way to increase sheep muscle growth and improve meat production rate.

\section{Conflicts of interest}

The authors declare no conflict of interest. 


\section{ACKNOWLEDGMENTS}

Research supported by the Xinjiang Uygur Autonomous Region International Cooperation projects "The research of MSTN propeptide protein promotes muscle growth of meat sheep" (\#20136004).

\section{REFERENCES}

El-Deiry WS, Tokino T, Velculescu VE, Levy DB, et al. (1993). WAF1, a potential mediator of p53 tumor suppression. Cell 75: 817-825. http://dx.doi.org/10.1016/0092-8674(93)90500-P

Ge X, McFarlane C, Vajjala A, Lokireddy S, et al. (2011). Smad3 signaling is required for satellite cell function and myogenic differentiation of myoblasts. Cell Res. 21: 1591-1604. http://dx.doi.org/10.1038/cr.2011.72

Gulbis JM, Kelman Z, Hurwitz J, O’Donnell M, et al. (1996). Structure of the C-terminal region of p21(WAF1/CIP1) complexed with human PCNA. Cell 87: 297-306. http://dx.doi.org/10.1016/S0092-8674(00)81347-1

Kambadur R, Sharma M, Smith TP and Bass JJ (1997). Mutations in myostatin (GDF8) in double-muscled Belgian Blue and Piedmontese cattle. Genome Res. 7: 910-916.

Langley B, Thomas M, Bishop A, Sharma M, et al. (2002). Myostatin inhibits myoblast differentiation by down-regulating MyoD expression. J. Biol. Chem. 277: 49831-49840. http://dx.doi.org/10.1074/jbc.M204291200

Lee SJ and McPherron AC (2001). Regulation of myostatin activity and muscle growth. Proc. Natl. Acad. Sci. USA 98: 9306-9311. http://dx.doi.org/10.1073/pnas.151270098

Li Z, Zhao B, Kim YS, Hu CY, et al. (2010). Administration of a mutated myostatin propeptide to neonatal mice significantly enhances skeletal muscle growth. Mol. Reprod. Dev. 77: 76-82. http://dx.doi.org/10.1002/mrd.21111

Liu D, Black BL and Derynck R (2001). TGF-beta inhibits muscle differentiation through functional repression of myogenic transcription factors by Smad3. Genes Dev. 15: 2950-2966. http://dx.doi.org/10.1101/gad.925901

Livak KJ and Schmittgen TD (2001). Analysis of relative gene expression data using real-time quantitative PCR and the 2(-Delta Delta C(T)) Method. Methods 25: 402-408. http://dx.doi.org/10.1006/meth.2001.1262

Magee CC and Sayegh MH (1997). Peptide-mediated immunosuppression. Curr. Opin. Immunol. 9: 669-675. http:// dx.doi.org/10.1016/S0952-7915(97)80047-7

McPherron AC, Lawler AM and Lee SJ (1997). Regulation of skeletal muscle mass in mice by a new TGF-beta superfamily member. Nature 387: 83-90. http://dx.doi.org/10.1038/387083a0

Tian L, Li JY, Xu SZ and Yue WB (2005). Research progress of animal production decision factor. Huang Niu Za Zhi 31: 43-46.

Yang J, Ratovitski T, Brady JP, Solomon MB, et al. (2001). Expression of myostatin pro domain results in muscular transgenic mice. Mol. Reprod. Dev. 60: 351-361. http://dx.doi.org/10.1002/mrd.1097 